\title{
REMOTELY PILOTED AIRCRAFT SYSTEM AIR VEHICLE TYPE SELECTION
}

\author{
Nikolajs Glizde, Margarita Urbaha \\ Riga Technical University, Latvia \\ nikolajs.glizde@edu.rtu.lv, urbaha.margarita@gmail.com
}

\begin{abstract}
The research is focused on development of the Unmanned Aircraft System. For design purposes the Systems Engineering Approach is used. This paper describes concise research in the Unmanned Aircraft System air vehicle preliminary development phase. The design is focused on development of a micro Unmanned Aircraft System with long range and endurance capabilities. In the current paper UAS air vehicle type selection that meets all design requirements is described.
\end{abstract}

Keywords: aircraft design, unmanned, air vehicle, engineering approach, aerodynamics.

\section{Introduction}

This is the conceptual design phase, during which the air vehicle is designed with non-precise results. All parameters are determined based on a decision-making process and a selection technique.

The research is focused on development of a size, portable, hand launch Unmanned Aircraft System with enhanced capabilities of the air vehicle (efficient altitude, endurance, etc.) for similar system size. The main reason for development is that the current systems efficient flight altitude is limited by the payload. To obtain useful data, for some special purpose usage, the air vehicle flight altitude is limited. The efficient flight altitude made in the research project requirements is higher than for the current systems of similar size.

The flight endurance is a parameter that always limits the operator in some special situations when long, dull surveillance is necessary. In the research the air vehicle flight endurance will be extended searching solutions not only with bigger power supply, but also with aerodynamic solutions.

Using the Aircraft Engineering Design principles [1-6], the designer from the very beginning, according to the posed requirements, is managing the design in a correct way to reach the desired objectives by calculations and quantitative evaluation of the design objectives.

At this phase the air vehicle configuration will be determined. Although for the Unmanned Aircraft System, in the category of micro air vehicles, there are no former regulations, the design is restricted by the imposed requirements. The design should follow the imposed requirements, unless there is aproof that a specific requirement is not feasible [6].

Problem statement: Design the Unmanned Aircraft System with Intelligence, Surveillance, Target Acquisition and Reconnaissance functional capabilities and the requirements summarized in Table 1.

System design requirements

\begin{tabular}{|c|c|c|c|}
\hline No. & Parameter & Requirement & Desired construction \\
\hline 1. & MTOW & Up to $8 \mathrm{~kg}$ & $\begin{array}{l}\text { Manufactured from light, durable material, } \\
\text { that insures construction endurance on loads, } \\
\text { resistance to humidity and wet weather. }\end{array}$ \\
\hline 2. & Thrust/propulsion type & Electric motor & Electric motor with controller. \\
\hline 3. & Endurance & $>300 \mathrm{~min}$ & $\begin{array}{l}\text { Considering usage on standard weather } \\
\text { conditions and launch from MSL. }\end{array}$ \\
\hline 4. & Efficient altitude & $>300 \mathrm{~m}$ & $\begin{array}{l}\text { To insure covert usage, track and identify } \\
\text { object according to military standard. }\end{array}$ \\
\hline 5. & Launch height & $<5000 \mathrm{~m}$ & - \\
\hline 6. & Operational range & Up to $50 \mathrm{~km}$ & With data transfer. \\
\hline 7. & Payload & EO/IR camera & $\begin{array}{l}\text { Payload usable during day and night times, } \\
\text { weight up to } 400 \mathrm{~g} \text {. }\end{array}$ \\
\hline 8. & $\begin{array}{c}\text { Modular type air vehicle, } \\
\text { carriable in backpack in } \\
\text { disassembled state }\end{array}$ & $\begin{array}{l}\text { Assemble time: } \\
<10 \text { min (ready } \\
\text { for launch) }\end{array}$ & Portable RPA system. \\
\hline 9. & Launch type & Hand-launch & $\begin{array}{l}\text { System design as hand-launch but portable } \\
\text { catapult system should be envisaged. }\end{array}$ \\
\hline
\end{tabular}


In the design process, to choose the best design alternative, approach for decision making is made in five following steps $[2 ; 6]$ :

- Step 1. Determine all alternatives which should be included in this design phase.

- Step 2. Choose the best design, in this step the criteria are identified and defined.

- Step 3. In this step the metrics are defined for each criterion.

- Step 4. The values are determined for each criterion to define its importance against other criteria.

- Step 5. Choose alternative which has obtained the highest priority or value.

\section{Air Vehicle configuration alternatives (Step 1)}

Determine RPAS air vehicle optimal configuration.

Solution: at the beginning several RPAS air vehicle configurations are defined Configuration A, from which is a basic configuration [11]:

- Configuration A: conventional configuration, with propulsion, electric motor, two motors, tractor type motors, fixed motors, motors in wings, one wing, fixed wing, rectangular wing, wing with fixed setting angle, mid-wing, cantilever wing installation, tail, conventional tail, exchangeable landing pads, long single hull airframe, flaperons on wing, horizontal tail with elevators, vertical tail with ruder, electrical actuators, wooden (plywood) and composite material structure (Fig. 1);

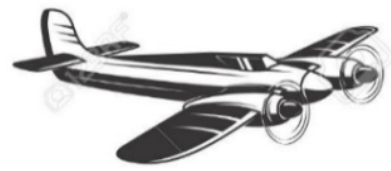

\section{Fig. 1. Visualization of Configuration A}

- Configuration B: conventional configuration, with propulsion, electric motor, one motor, tractor type motor, fixed motor, motor fore fuselage, one wing, immobile wing, tapered wing, wing with fixed setting angle, wing with fixed backward sweep angle, high wing, cantilever wing installation, tail, conventional tail, parachute landing system, long single hull airframe, flaperons on wing, horizontal tail with elevators, vertical tail with ruder, electrical actuators, wooden (plywood) and composite material structure (Fig. 2);

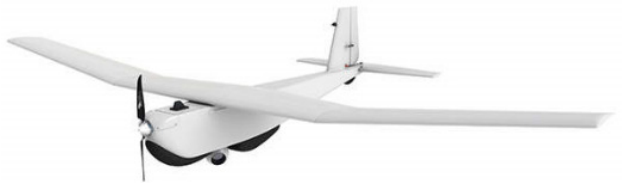

Fig. 2. Visualization of Configuration B

- Configuration C: conventional configuration, with propulsion, electric motor, one motor, pusher type motor, fixed motor, motor in middle of fuselage, one wing, immobile wing, tapered wing, wing with fixed setting angle, parasol wing, strut-braced wing installation, tail, conventional tail, exchangeable landing pads, deep stall landing, long hull with uplift on top, flaperons on wing, horizontal tail with elevators, vertical tail with ruder, electrical actuators, wooden (plywood) and composite material structure (Fig. 3);

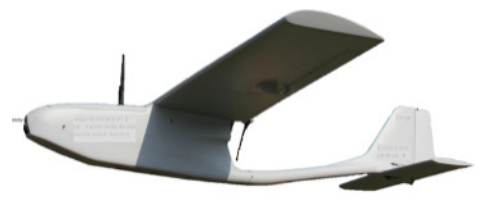

Fig. 3. Visualization of Configuration $\mathbf{C}$

- Configuration D: non-conventional configuration, tailless flying wing configuration, with propulsion, electric motor, one motor, pusher type motor, fixed motor, motor at fuselage aft, one wing, fixed wing, tapered wing, wing with fixed back sweep angle, wing with fixed setting angle, high/mid-wing, cantilever wing installation, tailless, winglets, exchangeable 
landing pads, deep stall landing, short hull with cover on top, flaperons/elevons on wing, without ruder (functionality provided by wing flaperons/elevons), electrical actuators, wooden (plywood) and composite material structure (Fig. 4);

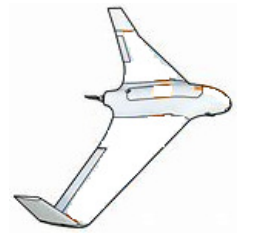

\section{Fig. 4. Visualization of Configuration D}

- Configuration E: non-conventional configuration, tailless flying wing configuration, with propulsion, electric motor, one motor, pusher type motor, fixed motor, motor at fuselage aft, one wing, fixed wing, tapered wing, wing with fixed back sweep angle, wing with fixed setting angle, high/mid-wing, cantilever wing installation, tailless, exchangeable landing pads, deep stall landing, short hull with cover on top, flaperons/elevons on wing, double vertical tail at wing root chords with rudders, electrical actuators, wooden (plywood) and composite material structure (Fig. 5);

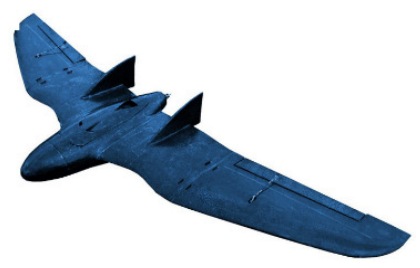

\section{Fig. 5. Visualization of Configuration $\mathbf{E}$}

- Configuration F: non-conventional configuration, tailless flying wing configuration, with propulsion, electric motor, one motor, pusher type motor, fixed motor, motor in aft of fuselage, one wing, fixed wing, tapered wing, wing with fixed back sweep angle, wing with fixed setting angle, high/mid-wing, cantilever wing installation, tailless, parachute landing system, short hull with cover on top, flaperons/elevons on wing, vertical tail at wing tips with rudders, electrical actuators, wooden (plywood) and composite material structure (Fig. 6);

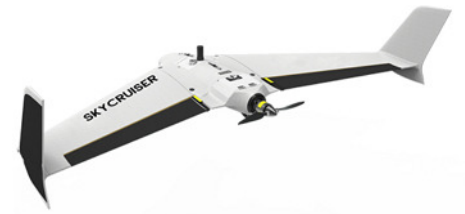

\section{Fig. 6. Visualization of Configuration $\mathbf{F}$}

- Configuration G: non-conventional configuration, V-tail configuration, with propulsion, electric motor, one motor, pusher type motor, fixed motor, motor in aft of fuselage, one wing, fixed wing, tapered wing, elliptical wing, wing with fixed setting angle, high wing, cantilever wing installation, V-tail with ruddervators, exchangeable landing pads, deep stall landing, long hull with cover on top, tail at aft of fuselage, flaperons on wing, electrical actuators, wooden (plywood) and composite material structure (Fig. 7);

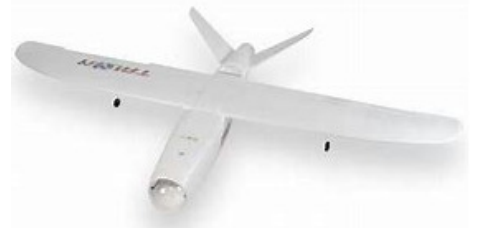

Fig. 7. Visualization of Configuration G

- Configuration H: non-conventional configuration, V-tail configuration, with propulsion, electric motor, one motor, pusher type motor, fixed motor, motor in aft of fuselage, one wing, 
immobile wing, tapered wing, elliptical wing, wing with fixed back sweep angle, wing with fixed setting angle, high wing, cantilever wing installation, V-tail with ruddervators, parachute landing system, long hull with cover on top, tail at aft of fuselage, flaperons on wing, electrical actuators, wooden (plywood) and composite material structure (Fig. 8).

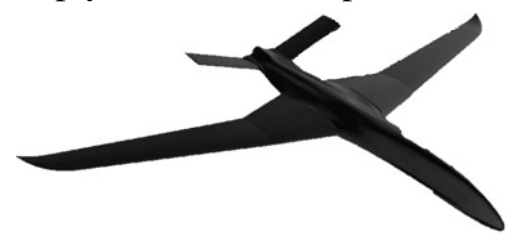

Fig. 8. Visualization of Configuration $\mathbf{H}$

\section{Identification of evaluation criteria (Step 2)}

At the beginning of the conceptual design phase the Technical Performance Measures or TPM are defined, which include the system design requirements. In $T P M$ are included: quality and quantity data, human factors, weight, geometry, volume, speed, process length, operational coast, maintenance coast, identifiability, manufacturability, obtainability $[1 ; 2 ; 6]$.

Table 2

\section{Evaluation criteria}

\begin{tabular}{|c|c|c|}
\hline No. & Technical performance measure & Objective \\
\hline 1. & Cost & $\begin{array}{l}\text { Minimum direct operating cost } \\
\text { Minimum total manufacturing cost } \\
\text { Minimum system lifecycle cost } \\
\text { Maximum payload per EUR }\end{array}$ \\
\hline 2. & Design and operation duration & $\begin{array}{l}\text { Minimum duration of design } \\
\text { Minimum duration of manufacture } \\
\text { Maximum aircraft operating life }\end{array}$ \\
\hline 3. & Weight & $\begin{array}{l}\text { Minimum take-off weight } \\
\text { Minimum empty weight } \\
\text { Maximum fuel weight }\end{array}$ \\
\hline 4. & Performance & $\begin{array}{l}\text { Maximizing cruise speed } \\
\text { Maximizing range } \\
\text { Maximizing endurance } \\
\text { Maximizing absolute ceiling } \\
\text { Minimizing take-off run } \\
\text { Maximizing rate of climb } \\
\text { Maximizing maneuverability }\end{array}$ \\
\hline 5. & Flying qualities & $\begin{array}{l}\text { Most controllable } \\
\text { Most stable }\end{array}$ \\
\hline 6. & Beauty or scariness & Most attractive \\
\hline 7. & Maintainability & $\begin{array}{l}\text { Most maintainable } \\
\text { Most flexible (growth potential) } \\
\text { Most reliable }\end{array}$ \\
\hline 8. & Producibility (ease of construction) & Most producible \\
\hline 9. & Disposability(Size) & $\begin{array}{l}\text { Smallest wing span } \\
\text { Smallest fuselage length } \\
\text { Smallest aircraft height } \\
\text { Most specious fuselage }\end{array}$ \\
\hline 10. & Stealth & Most stealthy \\
\hline
\end{tabular}

The technical performance measures shown in Table 2 will be evaluated against each technical construction feature (airframe, wing tail, etc.) of the air vehicle. 
To obtain the final evaluation result, 10 design objectives are defined, for which also the priority levels are defined.

Table 3

Defined design objectives

\begin{tabular}{|c|l|c|c|}
\hline No. & \multicolumn{1}{|c|}{ Design objectives } & $\begin{array}{c}\text { Weighed } \\
\text { value, } \%\end{array}$ & Priority \\
\hline 1. & Cost, $P_{C}$ & 9 & 6 \\
\hline 2. & Period of design, $P_{T}$ & 4 & 8 \\
\hline 3. & Aircraft weight, $P_{W}$ & 7 & 7 \\
\hline 4. & Performance, $P_{P}$ & 15 & 3 \\
\hline 5. & Flying qualities, $P_{F}$ & 20 & 1 \\
\hline 6. & Beauty, or scariness, $P_{B}$ & 1 & 10 \\
\hline 7. & Maintainability, $P_{M}$ & 14 & 4 \\
\hline 8. & Producibility, ease of construction, $P_{R}$ & 10 & 5 \\
\hline 9. & Disposability, $P_{D}$ & 2 & 9 \\
\hline 10. & Stealth, $P_{S}$ & 18 & 2 \\
\hline
\end{tabular}

It is very possible that during the design process it will be necessarily to make changes in the components that in turn will make changes in the air vehicle weight and gravitational center. If changes are made, it will be necessary to evaluate the air vehicle center of gravity to keep the correct trajectory. The requirements, to which it is necessary to pay the main attention, are performance, stability and controllability $[1 ; 10]$.

In Table 4 the configuration parameters are listed with their possible design alternatives, which will be finalized during the design process. During the optimization process the best configuration will be found and approved. In optimization the method will be used, which allows to choose the configuration parameters that coincide with the design requirements in the most optimal way.

The following table shows the configuration parameters and their possible design alternatives.

\section{Configuration parameters}

Table 4

\begin{tabular}{|c|l|l|}
\hline No. & Configuration parameter & \multicolumn{1}{|c|}{ Configuration parameter alternative } \\
\hline 1. & Conventionality & (i) Conventional and (ii) unconventional \\
\hline 2. & Propulsion & (i) With propulsion \\
\hline 3. & Engine & (i) Electric motor \\
\hline 4. & Engine number & (i) One, (ii) two \\
\hline 5. & Engine and air vehicle CG & (i) Pusher and (ii) tractor \\
\hline 6. & Engine mounting & (i) Fixed \\
\hline 7. & Engine position & (i) On airframe, (ii) inside airframe \\
\hline 8. & Wing number & (i) One \\
\hline 9. & Wing type & (i) Fixed wing \\
\hline 10. & Wing geometry & (i) Strait, (ii) tapered, (iii) swept, and (iv) delta wing \\
\hline 11. & Wing sweep & (i) Fixed sweep and (ii) adjustable sweep \\
\hline 12. & Wing setting angle & (i) Fixed \\
\hline 13. & Wing position & (i) High, (ii) low, (iii) mid, and (iv) parasol wing \\
\hline 14. & Wing mounting & (i) Cantilever and (ii) with struts \\
\hline 15. & Tail or canard type & (i) Tail, (ii) canard, and (iii) tree surface \\
\hline 16. & Tail type & (i) Conventional, (ii) T-type, (iii) H-type, (iv) V-type, and \\
& (v) + shape, etc. \\
\hline 17. & Vertical tail & $\begin{array}{l}\text { (i) Without vertical tail (VT), (ii) one VT in airframe aft, (iii) } \\
\text { two VT in airframe aft, and (iv) two VT on wing tips }\end{array}$ \\
\hline 18. & Landing gear & (i) Parachute, (vi) airbag, (viii) exchangeable landing pads. \\
\hline 19. & Airframe & (i) One short airframe, (ii) one long airframe \\
\hline 20. & Cargo/payload mounting & Based on payload types multiple solutions can be found. \\
\hline
\end{tabular}


Table 4 (continued)

\begin{tabular}{|c|l|l|}
\hline No. & Configuration parameter & \multicolumn{1}{c|}{ Configuration parameter alternative } \\
\hline 21. & $\begin{array}{l}\text { Horizontal tail control } \\
\text { surfaces }\end{array}$ & (i) Tail and elevator and (ii) multimoving horizontal tail. \\
\hline 22. & $\begin{array}{l}\text { Vertical tail control } \\
\text { surfaces }\end{array}$ & (i) Vertical tail and ruder and (ii) multimoving vertical tail \\
\hline 23. & Wing control surfaces & (i) Aileron and flap and (ii) flaperon \\
\hline 24. & Wing-tail control surfaces & $\begin{array}{l}\text { (i) Conventional (elevator, aileron, and ruder), (ii) ruddervator, } \\
\text { (iii) elevon, (iv) split rudder, and (v) thrust-vectored. }\end{array}$ \\
\hline 25. & Drive system & (i) Electric actuators, (ii) electric actuators with wi-fi \\
\hline 26. & Construction materials & $\begin{array}{l}\text { (i) Composite, (ii) wood/plywood, (ii) primary structure: foam, } \\
\text { secondary structure: composite, (i) metal, }\end{array}$ \\
\hline
\end{tabular}

During the design process it is necessary to determine the air vehicle type with its complete technical specification. If the air vehicle type is chosen correctly, then the further design process will be easier and helps avoid misunderstandings in the following design phases. The air vehicle type depends on the operational tasks and design requirements.

\section{Determination of the design objective values (Step 4)}

With the methodology used it is possible to estimate the characteristics of systems comparing several designs in a quantitative way. To ensure that the chosen configuration type after the obtained calculations is the configuration, which is searched for in this phase, the appropriate methodology and procedure should be followed. Every parameter is evaluated by a number between 0 and 1 . The preference percentages are divided among all preferences in the way that their summation equals $100 \%[2 ; 3 ; 10]$. Each objective index is the summation of the contributions of each configuration parameter:

$$
\begin{aligned}
& C I=\sum_{i=1}^{10} x_{C_{i}}, \\
& P I=\sum_{i=1}^{10} x_{P_{i}}, \\
& F I=\sum_{i=1}^{10} x_{F_{i}}, \\
& T I=\sum_{i=1}^{10} x_{T_{i}}, \\
& B I=\sum_{i=1}^{10} x_{B_{i}}, \\
& M I=\sum_{i=1}^{10} x_{M_{i}}, \\
& R I=\sum_{i=1}^{10} x_{R_{i}}, \\
& W I=\sum_{i=1}^{10} x_{W_{i}}, \\
& D I=\sum_{i=1}^{10} x_{D_{i}},
\end{aligned}
$$




$$
S I=\sum_{i=1}^{10} x_{S_{i}}
$$

where $C I-$ cost index and $x_{C i}$ is the contribution of the $i$-th configuration parameter on the cost index;

$P I$ - performance index;

$F I$ - flying qualities index;

$T I$ - period of design index;

$B I-$ beauty (or scariness) index;

$M I$ - maintainability index;

$R I$ - producibility index;

$W I$ - weight index;

$D I$ - disposability index;

$S I-$ stealth index.

And, $x$ with each of the above-mentioned parameter indexes with i-th index is contribution of each $i$-th configuration parameter in each design objective (CI, PI, FI, etc.).

Among 10 (ten) design objectives, three objectives must be minimized, they are: cost, weight, and period of design:

$$
D I_{\min }=C I \times P_{C}+W I \times P_{W}+T I \times P_{T},
$$

where $P_{C}$ - cost priority parameter;

$P_{W}-$ weight priority parameter;

$P_{T}-$ period of design priority parameter.

The other seven design objectives must be maximized, they are: performance, flying qualities, beauty (or scariness), maintainability, producibility, disposability, and stealth:

$$
D I_{\max }=P I \times P_{P}+F I \times P_{F}+B I \times P_{B}+M I \times P_{M}+R I \times P_{R}+D I \times P_{D}+S I \times P_{S},
$$

where $P_{P}$ - performance priority parameter;

$P_{F}$ - flying quality priority parameter;

$P_{B}$ - beauty priority parameter;

$P_{M}$ - maintainability priority parameter;

$P_{R}$ - producibility priority parameter;

$P_{D}$ - disposability priority parameter;

$P_{S}-$ stealth priority parameter.

Each design option must be evaluated for the features and requirements that are important for the design. The weight assigned to each criterion depends on its significance for the application. Each rating is multiplied by a weight and totaled for the final selection. The design that yields the highest point is assumed as the best or optimum configuration.

To combine all objective indices in a comparable quantity, the design index (DI) is defined. All objectives that need to be minimized are grouped into one design index $\left(D I_{\min }\right)$, as it is shown in the equation (11), and, the design objectives that need to be maximized are grouped into the design index $\left(D I_{\max }\right)$, as it is shown in the equation (12).

The variables $P_{x}$ in the equations (11) and (12) represent the priorities of the objective x in the design process and are shown in Table 3.

The design objective priorities that are essential to be minimum:

$$
P_{\min }=P_{C}+P_{W}+P_{T} .
$$

And, the design objective priorities that are essential to be maximized:

$$
P_{\max }=P_{P}+P_{F}+P_{B}+P_{M}+P_{R}+P_{D}+P_{S}
$$


Accordingly, for each design objective the weighed value is assigned considering its design priority. The design priority values that should be minimized add up to $20 \%$ and that ones that should be maximized $-80 \%$.

In order to determine the optimum configuration, the configuration at which the design index $(D I)$ is at the optimum value will be considered. The air vehicle configuration type, for which the objective priority summation is the highest, will be the selected configuration for further design. From the calculation equations (11) and (12) it is seen that there are two values that determine optimum design. These are $D I_{\min }$ and $D I_{\max }$. The selection of the optimal configuration depends on the obtained values of $D I_{\min }$ and $D I_{\max }$. In this case, when the variable $P_{\max }$ is larger than $P_{\min }$, from the defined priorities and their corresponding weighed values, the configuration, at which the design index $D I_{\max }$ is the highest, will be selected for the further design process as the optimal configuration $[1 ; 2 ; 8 ; 10]$.

\section{Results and discussion (Step 5)}

Considering the above mentioned air vehicle configuration types, configuration alternatives and design objectives, the table is put together [7;9].

Design parameter table

Table 5

\begin{tabular}{|c|c|c|c|c|c|c|c|c|c|}
\hline \multirow{2}{*}{ No. } & \multirow{2}{*}{$\begin{array}{c}\text { Configuration parameter } \\
\left(x_{C i}\right)\end{array}$} & \multicolumn{8}{|c|}{ Configuration type } \\
\hline & & $\mathbf{A}$ & B & $\mathbf{C}$ & D & $\mathbf{E}$ & $\mathbf{F}$ & G & $\mathbf{H}$ \\
\hline \multirow[t]{3}{*}{1.} & Design type: & - & - & - & - & - & - & - & - \\
\hline & 1. conventional & -2 & 0 & -2 & - & - & - & - & - \\
\hline & 2. non-conventional & - & - & - & 7 & 4 & 3 & 4 & 4 \\
\hline \multirow[t]{2}{*}{2.} & Propulsion: & - & - & - & - & - & - & - & - \\
\hline & 3. electric motor & -5 & -5 & -5 & 7 & 1 & 1 & 3 & 3 \\
\hline \multirow[t]{3}{*}{3.} & Engine number: & - & - & - & - & - & - & - & - \\
\hline & 4. one & - & -4 & -4 & 4 & -2 & -2 & -2 & -2 \\
\hline & 5. two & -3 & - & - & - & - & - & - & - \\
\hline \multirow[t]{5}{*}{4.} & Engine position: & - & - & - & - & - & - & - & - \\
\hline & 6. on wings & 4 & - & - & - & - & - & - & - \\
\hline & 7. airframe fore & - & -3 & - & - & - & - & - & - \\
\hline & 8. airframe aft & - & - & - & 8 & 8 & 8 & 8 & 8 \\
\hline & 9. in mid of airframe & - & - & -11 & - & - & - & - & - \\
\hline \multirow[t]{13}{*}{5.} & Wings: & - & - & - & - & - & - & - & - \\
\hline & wing number: & - & - & - & - & - & - & - & - \\
\hline & 10. one & 1 & 1 & 1 & 4 & 2 & 2 & 4 & 4 \\
\hline & wing shape: & - & - & - & - & - & - & - & - \\
\hline & 11. rectangular & -3 & - & - & - & - & - & - & - \\
\hline & 12. tapered & - & -5 & -6 & 10 & 1 & 1 & -1 & -2 \\
\hline & 13. elliptical & - & - & - & - & - & - & 2 & 7 \\
\hline & 14. defined back sweep & - & 1 & 0 & 2 & 2 & 2 & 0 & 1 \\
\hline & 15. defined setting angle & -1 & 0 & 0 & 1 & 2 & 2 & -1 & -1 \\
\hline & wing location: & - & - & - & - & - & - & - & - \\
\hline & 16. mid & - & - & - & 8 & 8 & 8 & - & - \\
\hline & 17. high & 1 & 1 & - & - & - & - & 1 & 1 \\
\hline & 18. parasol & - & - & -3 & - & - & - & - & - \\
\hline \multirow[t]{5}{*}{6.} & Tail: & - & - & - & - & - & - & - & - \\
\hline & 19. conventional & 7 & 7 & 5 & - & - & - & - & - \\
\hline & 20. non-conventional & - & - & - & - & - & - & 4 & 6 \\
\hline & horizontal tail: & - & - & - & - & - & - & - & - \\
\hline & 21. fuselage aft & 4 & 4 & 4 & - & - & - & 8 & 8 \\
\hline
\end{tabular}


Table 5 (continued)

\begin{tabular}{|c|c|c|c|c|c|c|c|c|c|}
\hline \multirow{2}{*}{ No. } & Configuration parameter & \multicolumn{9}{|c|}{ Configuration type } \\
\cline { 3 - 9 }$\left(\boldsymbol{x}_{\boldsymbol{C}}\right)$ & $\mathbf{A}$ & $\mathbf{B}$ & $\mathbf{C}$ & $\mathbf{D}$ & $\mathbf{E}$ & $\mathbf{F}$ & $\mathbf{G}$ & $\mathbf{H}$ \\
\hline & horizontal tail type: & - & - & - & - & - & - & - & - \\
\hline & 22. with elevator & 2 & 2 & 2 & - & - & - & - & - \\
\hline & 23. V-shape & - & - & - & - & - & - & 2 & 5 \\
\hline & 24. tailless & - & - & - & 10 & 6 & 6 & - & - \\
\hline & vertical tail: & - & - & - & - & - & - & - & - \\
\hline & 25. fuselage aft & -2 & -2 & -1 & - & - & - & 8 & 8 \\
\hline & 26. on wing & - & - & - & - & 5 & 5 & - & - \\
\hline & vertical tail type: & - & - & - & - & - & - & - & - \\
\hline & 27. fixed & - & - & - & 8 & - & - & - & - \\
\hline & 28. with ruder/ruddervator & 3 & 4 & 3 & - & 3 & 3 & - & - \\
\hline 7. & Landing gear: & - & - & - & - & - & - & - & - \\
\hline & 29. exchangeable pads & -4 & - & -4 & 7 & 5 & - & -2 & - \\
\hline & 30. parachute system & - & 0 & - & - & - & 0 & - & 0 \\
\hline 8. & Fuselage: & - & - & - & - & - & - & - & - \\
\hline & 31. long airframe & -2 & -2 & - & - & - & - & -2 & -2 \\
\hline & 32. short airframe & - & - & -2 & 10 & 9 & 10 & - & - \\
\hline 9. & Actuators: & - & - & - & - & - & - & - & - \\
\hline & 33. electric & -7 & -6 & -8 & 9 & 8 & 8 & -1 & -1 \\
\hline 10. & Construction materials: & - & - & - & - & - & - & - & - \\
\hline & 34. composites & -2 & -2 & -2 & 2 & 2 & 2 & -2 & -2 \\
\hline & 35. wood/plywood & -3 & -3 & -3 & 3 & 3 & 3 & 0 & 0 \\
\hline & 36. foam & -3 & -2 & -2 & 4 & 6 & 6 & 0 & 0 \\
\hline
\end{tabular}

In Table 5 the air vehicle construction features are evaluated using numbers 1,0 and -1 . The number " 1 " indicates that this feature has positive influence on a particular TPM objective. The number " 0 " indicates that this feature does not have any influence on a particular TPM objective or is not considered in the particular case. The number "- 1 " indicates that this feature has negative influence on particular TPM objective. In Table 6 the summation values that refer to the design index $D I_{\max }$ are shown [3-5].

The main aim in this design phase of the research is to find the best configuration that satisfies the design requirements.

The calculation result is shown in Table 6 .

As it was mentioned above, if the design objective priority $P_{\max }$ is larger than $P_{\min }$, then the optimal configuration is determined from the configuration which has obtained the maximum design index value $D I_{\max }$. The obtained result of the air vehicle configuration type $\mathrm{D}$ gives information of the optimal configuration for general point of view.

To design an air vehicle that really gives the expected performance, reliability and maintenance results, the attention should be paid to the design criteria points, which have obtained a negative or low value and find a technical solution, which will eliminate completely or at least partly the mentioned deficiencies.

For example, the selected configuration type $\mathrm{D}$ is a flying tailless wing. The legacy deficiency for this type of air vehicle is poor stability and control characteristics. That can be partly solved selecting the right wing airfoil type.

In further design phases attention should be paid to the following deficiencies found during the air vehicle type selection process:

1. flying qualities (control and stability);

2. performance (rate of clime, maneuverability, etc.);

3. landing system. 
Design parameter table

\begin{tabular}{|c|l|c|c|c|c|c|c|c|c|c|}
\hline No. & \multicolumn{1}{|c|}{$\begin{array}{c}\text { Technical } \\
\text { parameter }\end{array}$} & $\begin{array}{c}\text { Weighed } \\
\text { value, \% }\end{array}$ & $\mathbf{A}$ & $\mathbf{B}$ & $\mathbf{C}$ & $\mathbf{D}$ & $\mathbf{E}$ & $\mathbf{F}$ & $\mathbf{G}$ & $\mathbf{H}$ \\
\hline 1. & Cost $(C I)$ & 9 & -2.79 & -1.71 & -1.08 & 4.14 & 2.43 & 1.62 & 0.09 & -0.54 \\
\hline 2. & Period of design $(T I)$ & 4 & 0.36 & 0.24 & 0.52 & 0.68 & 0.52 & 0.36 & 0.6 & 0.24 \\
\hline 3. & Aircraft weight $(W I)$ & 7 & -2.1 & -2.03 & -1.33 & 2.52 & 1.96 & 0.7 & -1.05 & -1.75 \\
\hline \multicolumn{1}{|c|}{$D I_{\text {min }}$ : } & $\mathbf{2 0}$ & $\mathbf{- 4 . 5}$ & $\mathbf{- 3 . 5}$ & $\mathbf{- 1 . 9}$ & $\mathbf{7 . 3}$ & $\mathbf{4 . 9}$ & $\mathbf{2 . 7}$ & $\mathbf{- 0 . 4}$ & $\mathbf{- 2 . 1}$ \\
\hline 4. & Performance $(P I)$ & 15 & 0.3 & 1.35 & 0.3 & 5.7 & 6 & 5.1 & 0.75 & 2.4 \\
\hline 5. & Flying qualities $(F I)$ & 20 & 4.2 & 4.2 & 3.8 & -2.4 & 0 & 0 & 3 & 3 \\
\hline 6. & $\begin{array}{l}\text { Beauty (or scariness) } \\
\text { (BI) }\end{array}$ & 1 & -0.11 & -0.11 & -0.11 & 0.1 & 0.06 & 0.07 & 0.05 & 0.07 \\
\hline 7. & Maintainability $(M I)$ & 14 & -0.32 & -0.38 & -0.41 & 0.49 & 0.18 & 0.17 & -0.07 & -0.06 \\
\hline 8. & $\begin{array}{l}\text { Producibility }(\text { ease } \\
\text { of construction) }(R I)\end{array}$ & 10 & 0 & -0.3 & -0.3 & 1.2 & 0.4 & 0.4 & 0 & -0.3 \\
\hline 9. & Disposability $(D I)$ & 2 & 0.1 & 0.12 & -0.14 & 0.24 & 0.26 & 0.26 & 0.04 & 0.06 \\
\hline 10. & Stealth $(S I)$ & 18 & -2.16 & -1.98 & -1.98 & 1.62 & -0.54 & -0.36 & -0.9 & -0.9 \\
\hline \multicolumn{1}{|c|}{$D I_{\text {max }}$ : } & $\mathbf{8 0}$ & $\mathbf{2 . 0}$ & $\mathbf{2 . 9}$ & $\mathbf{1 . 2}$ & $\mathbf{6 . 9}$ & $\mathbf{6 . 4}$ & $\mathbf{5 . 6}$ & $\mathbf{2 . 9}$ & $\mathbf{4 . 3}$ \\
\hline
\end{tabular}

The research further will be focused on the wing design. At the beginning the wing airfoil section will be selected. Possibly the wing will be designed from more than one airfoil sections (two). After the wing airfoil section is selected, the wing planform will be designed and tested in Computational Fluid Dynamics software. In case the results are satisfactory, the design will be continued with the airframe design. Considering that the design objective is long endurance (Performance quality), it is very possible that a winglet will also be necessary to design. Winglet should enhance such flight performance qualities as gliding flight and rate of clime [12].

Referring to the $3^{\text {rd }}$ point of the issue - the landing system, that also is problem of flying wing aircrafts because of inherently small stall angle. If this does not cause the problem during take-off then that is not very good for landing stages because the landing place should be carefully selected that can be problematic if the operation is conducted in arboreous or woody area. Traditionally for this type of UAV systems the air vehicle landing is completed in the following ways: deep stall, catching in the net, catching with the hook system and parachute landing. In this research new solution for landing will be searched.

Prospectively a complete flight dynamics model will be designed in MATLAB and SIMULINK (JSBSim) for accurate numerous flight performance characteristics evaluation to evaluate the expected performance in differing air vehicle states, evaluation of the obtained research results anddetermination of further design steps [12].

\section{Conclusions}

The obtained result is the initial step in the design process. It does not give the final answer to the question, if the design objectives are reachable. Possibly the further design process will show that there is necessity to utilize other alternatives. If this is the case, then possible alternatives from Table 4 will be used.

Also, the systems engineering approach optimization method in this case is used, good knowledge in airplane aerodynamics and performance is essential.

\section{Acknowledgements}

This work has been supported by the European Regional Development Fund within the Activity 1.1.1.2 "Post-doctoral Research Aid" of the Specific Aid Objective 1.1.1 "To increase the research and innovative capacity of scientific institutions of Latvia and the ability to attract external financing, investing in human resources and infrastructure" of the Operational Program "Growth and Employment" (No. 1.1.1.2/VIAA/1/16/176 "Multifunctional Nanostructured Coatings for Aircraft Structures (NANOCOAIRS)") 


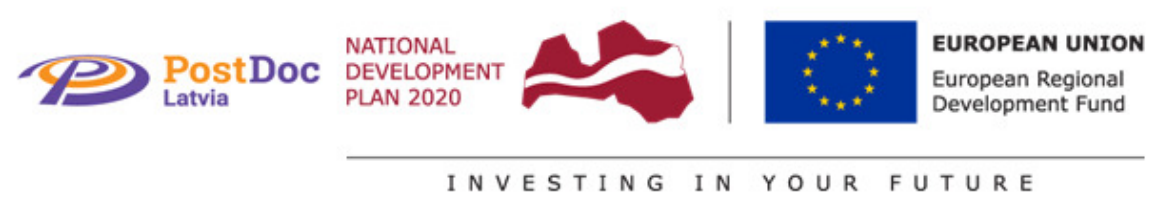

\section{References}

[1] Sadraey M., Aircraft Design, John Wiley \& Sons, Ltd, 2013, 800 p.

[2] Sadraey M., Aircraft Performance Analysis, VDM Verlag Dr. Müller, 2009, 476 p.

[3] Lan E.C.T. and Roskam J., Airplane Aerodynamics and Performance, DAR Corporation, 2003, $743 \mathrm{p}$.

[4] Roskam J., Airplane Design, vol. I, DAR Corporation, 2005, 226 p.

[5] Bertin L.J., Cummings R.M., Aerodynamics for Engineers, 5th edn, Pearson/Prentice Hall, 2009, $757 \mathrm{p}$.

[6] Blanchard B.S. Fabrycky W.J., Systems Engineering and Analysis, 4th edn, Prentice Hall, 2006, $800 \mathrm{p}$.

[7] Groover M.P., Fundamentals of Modern Manufacturing: Materials, Processes, and Systems, 4thedn, John Wiley \& Sons, Inc., 2010, 1024 p.

[8] Kroo I., Altus S., Braun R. et al., Multidisciplinary Optimization Methods for Aircraft Preliminary Design, 1994, AIAA 94-4325.

[9] Rao C., Tsai H., Ray T., Aircraft configuration design using a multidisciplinary optimization approach, 42nd AIAA Aerospace Sciences Meeting and Exhibit, Reno, NV, January 5-8, 2004, AIAA-2004-536.

[10] Roskam J., Lessons Learned in Aircraft Design, DAR Corporation, 2007, 512 p.

[11] Jackson P. Jane's All the World's Aircraft, Jane's Information Group, various years (1996-2011), $877 \mathrm{p}$.

[12] Nicolosi F., De Marco A., Vecchia P.D. The Role of Flight Tests and of Flight Simulation in Aircraft Design, University of Naples "Federico II", DepartmentofAerospaceEngineering(DIAS), AircraftDesign \&AeroflightdynamicsGroup (ADAG), 2011, 56 p.

[13] Urbahs A., Jonaite I. Features of the use of unmanned aerial vehicles for agriculture applications, Aviation, ISSN 1648-7788 print/ISSN $1822-4180$ online, 2013, Volume 17, Nr.4, DOI: 10.3846/16487788.2013.861224, 2013, pp.170-175.

[14]Urbahs A., Žavtkēvičs V., Remotely Piloted Aircraft route optimization when performing oil pollution monitoring of the sea aquatorium, Aviation, 21 (2), DOI: 10.3846/16487788.2017.1344139, 2017, pp.70-74.

[15] Urbahs A., Zavtkevics V., Remote Piloted Aircraft Using for Sampling of Oil Spill,in: Transport Means 2017: Proceedings of the 21st International Scientific Conference, Lithuania, Kaunas, 2022 September 2017. Kaunas: Kaunas University of Technology, ISSN 1822-296X, 2017, pp.489492. 